\title{
Air Pollution and Preterm Birth: Do Air Pollution Changes over Time Influence Risk in Consecutive Pregnancies among Low-Risk Women?
}

\author{
Pauline Mendola ${ }^{1, * \mathbb{D}}$, Carrie Nobles ${ }^{1}$, Andrew Williams ${ }^{1}{ }^{\mathbb{D}}$, Seth Sherman $^{2}{ }^{\mathbb{D}}$, \\ Jenna Kanner ${ }^{1}{ }^{\mathbb{D}}$, Indulaxmi Seeni ${ }^{3}$ and Katherine Grantz ${ }^{1}$ \\ 1 Division of Intramural Population Health Research, Epidemiology Branch, Eunice Kennedy Shriver National \\ Institute of Child Health and Human Development, 6710B Rockledge Drive, Bethesda, MD 20895, USA; \\ Carrie.nobles@nih.gov (C.N.); andrew.d.williams@aol.com (A.W.); m.kanner@nih.gov (J.K.); \\ katherine.grantz@nih.gov (K.G.) \\ 2 The Emmes Company, 401 N Washington St \# 700, Rockville, MD 20850, USA; ssherman@emmes.com \\ 3 University of California Davis School of Medicine, 4610 X Street, Sacramento, CA 95817, USA; \\ icseeni@gmail.com \\ * Correspondence: pauline.mendola@nih.gov
}

Received: 19 July 2019; Accepted: 24 August 2019; Published: 12 September 2019

\begin{abstract}
Since the 2000s, air pollution has generally continued to decrease in the U.S. To investigate preterm birth (PTB) risk associated with air pollutants in two consecutive pregnancies, we estimated exposures using modified Community Multiscale Air Quality models linked to the NICHD Consecutive Pregnancy Study. Electronic medical records for delivery admissions were available for 50,005 women with singleton births in 20 Utah-based hospitals between 2002-2010. We categorized whole pregnancy average exposures as high ( $>75$ th percentile), moderate $(25-75)$ and low $(<25)$. Modified Poisson regression estimated second pregnancy PTB risk associated with persistent high and moderate exposure, and increasing or decreasing exposure, compared to persistent low exposure. Analyses were adjusted for prior PTB, interpregnancy interval and demographic and clinical characteristics. Second pregnancy PTB risk was increased when exposure stayed high for sulfur dioxide $(32 \%)$, ozone $(17 \%)$, nitrogen oxides $(24 \%)$, nitrogen dioxide $(43 \%)$, carbon monoxide $(31 \%)$ and for particles $<10$ microns $(29 \%)$ versus consistently low exposure. PTB risk tended to increase to a lesser extent for repeated PTB (19-21\%) than for women without a prior PTB (22-79\%) when exposure increased or stayed high. Area-level changes in air pollution exposure appear to have important consequences in consecutive pregnancies with increasing exposure associated with higher risk.
\end{abstract}

Keywords: air pollution; preterm birth; pregnancy; sulfur dioxide; ozone; nitrogen oxides; carbon monoxide; particulate matter

\section{Introduction}

Preterm birth has been associated with air pollution exposure, but no prior studies have examined the change in risk over time in an existing cohort. The NICHD Consecutive Pregnancy Study (2002-2010) contains detailed clinical data on deliveries for more than 50,000 women with at least two pregnancies during the study period [1]. On average, criteria air pollutants in the United States (U.S.) decreased over the 2000's [2] while the preterm birth rate peaked in 2006 at $12.8 \%$ and declined to $11.9 \%$ in 2010 [3]. During this period of dynamic change, we evaluated the air-pollution associated preterm birth risk in this cohort of low-risk women.

Considering that continued progress to improve air quality is challenged by the global impact of extreme weather events and climate change, which may increase pollution after decades of 
improvements, it is important to characterize the link between changes in exposure and population health to inform policy [4]. Even if anthropogenic air pollution stays constant, increases in ambient temperature will be associated with increased ozone $\left(\mathrm{O}_{3}\right)$ and precursors of particulate matter $<2.5$ microns $\left(\mathrm{PM}_{2.5}\right)$, as well as a higher incidence of wildfire exposures [5]. A recent meta-analysis reported whole pregnancy exposure to $\mathrm{O}_{3}$, carbon monoxide (CO) and particulate matter significantly increased preterm risk [6]. Preterm birth is an important population health indicator with a global incidence of 15 million births each year [7]. It is a leading cause of infant mortality and is associated with long-term adverse effects on neurodevelopment, cardiovascular, renal, metabolic and pulmonary health [8]. The rate of preterm birth is higher in the U.S. than in other developed countries, but changes to ambient environmental exposures, such as the retirement of power plants using fossil fuels [9], can further lower risk and mitigate disparities. Following women over time to determine if their preterm birth risks are potentially influenced by changing ambient air pollution can provide evidence on the potential effectiveness of pollution control measures to improve health outcomes.

In addition to the potential for changes in risk associated with the ambient environment, changes in preterm birth risk over time are also influenced by women's reproductive history. A recent meta-analysis reported an average absolute recurrent spontaneous preterm birth rate of $30 \%$ [10] and we observed a similar recurrence risk in the NICHD Consecutive Pregnancy Study data [1].

Our aim was to examine the risk of preterm birth in a second pregnancy based on the change in air pollutant exposure since the first birth in a cohort of low-risk U.S. women. This is important to demonstrate the human health impacts of improved or degraded air quality over time on preterm birth, a key indicator of population health. We hypothesized that improving air quality would be associated with a lower risk of subsequent preterm birth, and that increased preterm birth risk would be observed when air pollution stayed high over time. We also evaluated potential effect modification by prior preterm birth and hypothesized that women without a prior history, generally at lower risk, would have a higher preterm birth risk associated with air pollution exposure.

\section{Materials and Methods}

The NICHD Consecutive Pregnancy Study [1] is based on electronic medical records for hospital delivery admissions among 50,005 women with singleton births in 20 Utah-based hospitals from the same medical care system between 2002-2010. Institutional Review Board approval was obtained at all participating institutions, and the final dataset was anonymized. The first two consecutive pregnancies observed comprised the analytic dataset. Approximately $20 \%$ of women $(n=10,325)$ delivered at two different study hospitals, with $30 \%$ of those $(n=3112)$ associated with a hospital closure. All outcome and covariate information were derived from the medical records and discharge summaries. Preterm birth was defined as the best clinical estimate of gestational age $<37$ completed weeks.

Air pollution exposure was estimated for each pregnancy using modified Community Multi-Scale Air Quality models and averaged over the delivery hospital referral region fused with existing monitor data using inverse distance weighting [1]. Exposure models for sulfur dioxide $\left(\mathrm{SO}_{2}\right), \mathrm{O}_{3}$, nitrogen oxides $\left(\mathrm{NO}_{\mathrm{x}}\right)$, nitrogen dioxide $\left(\mathrm{NO}_{2}\right), \mathrm{CO}$, particulate matter $<10$ microns $\left(\mathrm{PM}_{10}\right)$, and particulate matter $<2.5$ microns $\left(\mathrm{PM}_{2.5}\right)$ were also weighted to reflect the population density in order to discount areas where women were unlikely to live or work.

Based on the exposure levels in the first observed pregnancy (Supplementary Material Table S1), we categorized whole pregnancy exposures as high ( $>75$ th percentile), moderate (25th to 75th percentile) and low ( $<25$ th percentile). Exposures were also calculated truncated at 28 gestational weeks (Supplementary Material Table S2) in order to consider the shorter gestational length for preterm births. Second pregnancies were evaluated based on first pregnancy cut points and characterized based on the change from the first pregnancy as stayed high (high in both pregnancies), stayed moderate (moderate in both pregnancies), increasing (moved from low or moderate to moderate or high) or decreasing (moved from high or moderate to moderate or low). Exposures that stayed low were the reference category. 
Relative risks and 95\% confidence intervals were estimated using single-pollutant, modified Poisson regression models with robust errors [11] to correct for the over-estimation of variance in a traditional Poisson model. We estimated second pregnancy preterm birth risk associated with whole pregnancy average persistent high and moderate exposure, and increasing or decreasing exposure, compared to persistent low exposure. Missing data were addressed using multiple imputations, using chained equations to generate ten datasets [12]. Analyses were run independently in each imputed dataset with the effect estimates and variability pooled to provide a summary estimate. Analyses were adjusted for prior preterm birth (yes/no in the first observed pregnancy), interpregnancy interval (years), and covariates recorded in the second pregnancy: maternal age (years), pre-pregnancy body mass index $\left(\mathrm{kg} / \mathrm{m}^{3}\right)$, race/ethnicity (Non-Hispanic white, Non-Hispanic black, Hispanic, Asian, other/unknown), marital status (married, unmarried), insurance status (public, private), parity $(1,2+)$, smoking and alcohol use during pregnancy (yes, no, unknown) and history of maternal asthma (yes/no).

Given the strength of prior preterm birth as a predictor of preterm birth in the second pregnancy, we repeated the main analyses evaluating interaction by prior preterm birth status. To assess the robustness of our findings, we also repeated the whole pregnancy average analyses using exposures truncated at 28 gestational weeks and examined the subset of consecutive pregnancies among nulliparas at study onset. To further explore the potential impact of changes over time on second pregnancy preterm birth risk, we evaluated year of conception for the second pregnancy, and the change in season of conception between the first and second pregnancy (stayed warm-reference, warm to cold, cold to warm and stayed cold).

All analyses were conducted using SAS 9.4 (SAS Institute, Cary, NC, USA).

\section{Results}

Infants were delivered preterm in $7.6 \%$ of both first and second observed pregnancies (Table 1). The women were generally low risk, with the majority Non-Hispanic white, married women with private insurance. Second pregnancy preterm births were more common among older mothers, women with slightly shorter inter-pregnancy intervals, non-white women, those who were unmarried and had public insurance, as well as mothers who were multiparous and reported smoking and alcohol use during pregnancy. As anticipated, having a prior preterm birth was associated with a higher proportion of preterm birth in the second pregnancy (30.6\%) compared with a prior term birth $(5.7 \%)$ and mothers with asthma were more likely to have a preterm birth.

Exposure to air pollutants were characterized as high, moderate and low based on the percentiles for whole pregnancy exposure in the first observed pregnancy (Supplementary Material Table S1). Pollutants levels tended to decrease between the first and second observed pregnancy, but the changes were not consistent in magnitude (Supplementary Material Table S2) with less decrease over time observed for $\mathrm{SO}_{2}, \mathrm{PM}_{10}$ and $\mathrm{PM}_{2.5}$. Overall, women were more likely to experience a decrease in pollutant exposure with approximately $7-12 \%$ of women having a category shift to higher exposure in the second pregnancy compared to 27-59\% shifting to a lower exposure category (Supplementary Material Table S3). $\mathrm{PM}_{2.5}$ was an exception, with a similar proportion of women, approximately $30 \%$, experiencing an increase and a decrease in exposure.

When exposures stayed high in both the first and second pregnancy, compared with persistent low exposure, the relative risk of preterm birth in the second pregnancy was significantly elevated for all pollutants except for $\mathrm{PM}_{2.5}$ (Table 2). The highest risks were observed for $\mathrm{NO}_{2}$ (43\% increase) and $\mathrm{SO}_{2}$ (32\% increase). When exposure stayed moderate, we observed an increased risk associated with $\mathrm{SO}_{2}\left(12 \%\right.$ increase) and a decreased risk for $\mathrm{PM}_{2.5}$ exposure (18\% decrease). Similar to the results for persistent high exposure, increasing exposure over time was generally associated with higher PTB risk, although the results for $\mathrm{NO}_{x}$ were not significant. Decreasing exposure over time resulted in lower risk estimates, although still significantly elevated for $\mathrm{SO}_{2}, \mathrm{NO}_{2}$ and $\mathrm{PM}_{10}$. For example, the relative risk for $\mathrm{SO}_{2}$ when exposure increased was 1.41 versus 1.17 when exposure decreased over time. 
Table 1. Characteristics of the study sample by preterm birth status in the second pregnancy among 50,005 mothers, NICHD Consecutive Pregnancy Study, 2002-2010.

\begin{tabular}{|c|c|c|c|c|c|}
\hline & \multicolumn{2}{|c|}{$\begin{array}{c}\text { Preterm Birth } \\
\mathrm{N}=3806(7.6 \%)\end{array}$} & \multicolumn{2}{|c|}{$\begin{array}{c}\text { No Preterm Birth } \\
\mathrm{N}=46,199(92.4 \%)\end{array}$} & \multirow[t]{2}{*}{$p$} \\
\hline & Mean & SD & Mean & SD & \\
\hline Age (years) & 28.1 & 4.6 & 27.8 & 5.1 & $<0.001$ \\
\hline BMI $\left(\mathrm{kg} / \mathrm{m}^{2}\right)$ & 25.1 & 5.7 & 25.2 & 6.2 & 0.32 \\
\hline \multirow[t]{2}{*}{ Interpregnancy interval (years) } & 2.39 & 1.11 & 2.50 & 1.01 & $<0.001$ \\
\hline & $\mathrm{N}$ & $\%$ & $\mathrm{~N}$ & $\%$ & \\
\hline Race/ethnicity & & & & & $<0.001$ \\
\hline Non-Hispanic white & 3210 & 84.3 & 39,905 & 86.4 & \\
\hline Non-Hispanic black & 25 & 0.7 & 190 & 0.4 & \\
\hline Hispanic & 438 & 11.5 & 4934 & 10.7 & \\
\hline Asian & 96 & 2.5 & 909 & 2 & \\
\hline Other/unknown & 37 & 1 & 261 & 0.6 & \\
\hline Marital status & & & & & $<0.001$ \\
\hline Married & 3223 & 94.7 & 41,869 & 90.6 & \\
\hline Not married & 583 & 15.3 & 4330 & 9.4 & \\
\hline Insurance & & & & & $<0.001$ \\
\hline Public & 1223 & 32.1 & 11,938 & 25.8 & \\
\hline Private & 2583 & 67.9 & 34,261 & 74.2 & \\
\hline Parity & & & & & $<0.001$ \\
\hline 1 & 1917 & 50.4 & 25,210 & 54.6 & \\
\hline $2+$ & 1889 & 49.6 & 20,989 & 45.4 & \\
\hline Smoking & & & & & $<0.001$ \\
\hline Yes & 285 & 7.5 & 1300 & 2.8 & \\
\hline No & 3517 & 92.4 & 44,856 & 97.1 & \\
\hline Unknown & 4 & 0.1 & 43 & 0.1 & \\
\hline Alcohol use & & & & & $<0.001$ \\
\hline Yes & 124 & 3.3 & 649 & 1.4 & \\
\hline No & 2671 & 96.5 & 45,428 & 98.3 & \\
\hline Unknown & 11 & 0.3 & 122 & 0.3 & \\
\hline PTB in prior pregnancy & & & & & $<0.001$ \\
\hline Yes & 1163 & 30.6 & 2623 & 5.7 & \\
\hline No & 2643 & 69.4 & 43,576 & 94.3 & \\
\hline Maternal asthma & & & & & $<0.001$ \\
\hline Yes & 325 & 8.5 & 2844 & 6.2 & \\
\hline No & 3481 & 91.5 & 43,355 & 93.8 & \\
\hline
\end{tabular}


Table 2. The adjusted relative risk of preterm birth in second pregnancy by change in whole pregnancy average criteria pollutant exposure levels from first to second pregnancy among 50,005 mothers, NICHD Consecutive Pregnancy Study, 2002-2010.

\begin{tabular}{|c|c|c|c|c|}
\hline \multirow[b]{2}{*}{$\begin{array}{l}\text { Change in Whole Pregnancy Exposure } \\
\text { from First to Second Observed Pregnancy }\end{array}$} & \multicolumn{4}{|c|}{ Second Pregnancy Preterm Birth } \\
\hline & $\mathbf{R R}$ & LCL & UCL & $p$ \\
\hline \multicolumn{5}{|l|}{ Stay high vs. stay low } \\
\hline $\mathrm{SO}_{2}$ & 1.32 & 1.17 & 1.49 & $<0.0001$ * \\
\hline $\mathrm{O}_{3}$ & 1.17 & 1.00 & 1.37 & 0.046 * \\
\hline $\mathrm{NO}_{\mathrm{x}}$ & 1.24 & 1.09 & 1.41 & $0.001 *$ \\
\hline $\mathrm{NO}_{2}$ & 1.43 & 1.27 & 1.61 & $<0.0001 *$ \\
\hline $\mathrm{CO}$ & 1.31 & 1.15 & 1.49 & $<0.0001 *$ \\
\hline $\mathrm{PM}_{2.5}$ & 1.05 & 0.90 & 1.22 & 0.53 \\
\hline $\mathrm{PM}_{10}$ & 1.29 & 1.14 & 1.45 & $<0.0001^{*}$ \\
\hline \multicolumn{5}{|l|}{ Stay moderate vs. stay low } \\
\hline $\mathrm{SO}_{2}$ & 1.12 & 1.01 & 1.24 & 0.024 \\
\hline $\mathrm{O}_{3}$ & 0.97 & 0.84 & 1.12 & 0.67 \\
\hline $\mathrm{NO}_{\mathrm{x}}$ & 0.89 & 0.78 & 1.00 & 0.053 \\
\hline $\mathrm{NO}_{2}$ & 0.93 & 0.83 & 1.05 & 0.25 \\
\hline $\mathrm{CO}$ & 0.89 & 0.79 & 1.00 & 0.06 \\
\hline $\mathrm{PM}_{2.5}$ & 0.82 & 0.73 & 0.93 & $0.002 *$ \\
\hline $\mathrm{PM}_{10}$ & 1.03 & 0.94 & 1.14 & 0.49 \\
\hline \multicolumn{5}{|l|}{ Increase vs. stay low } \\
\hline $\mathrm{SO}_{2}$ & 1.41 & 1.27 & 1.56 & $<0.0001 *$ \\
\hline $\mathrm{O}_{3}$ & 1.48 & 1.23 & 1.76 & $<0.0001$ * \\
\hline $\mathrm{NO}_{\mathrm{x}}$ & 1.13 & 0.99 & 1.28 & 0.06 \\
\hline $\mathrm{NO}_{2}$ & 1.45 & 1.28 & 1.65 & $<0.0001$ * \\
\hline $\mathrm{CO}$ & 1.51 & 1.31 & 1.74 & $<0.0001$ * \\
\hline $\mathrm{PM}_{2.5}$ & 0.96 & 0.86 & 1.08 & 0.54 \\
\hline $\mathrm{PM}_{10}$ & 1.22 & 1.10 & 1.35 & $0.0002 *$ \\
\hline \multicolumn{5}{|l|}{ Decrease vs. stay low } \\
\hline $\mathrm{SO}_{2}$ & 1.17 & 1.06 & 1.29 & $0.002 *$ \\
\hline $\mathrm{O}_{3}$ & 0.96 & 0.84 & 1.10 & 0.53 \\
\hline $\mathrm{NO}_{\mathrm{x}}$ & 1.02 & 0.91 & 1.15 & 0.71 \\
\hline $\mathrm{NO}_{2}$ & 1.12 & 1.01 & 1.25 & 0.039 * \\
\hline $\mathrm{CO}$ & 0.99 & 0.89 & 1.11 & 0.89 \\
\hline $\mathrm{PM}_{2.5}$ & 0.98 & 0.87 & 1.10 & 0.68 \\
\hline $\mathrm{PM}_{10}$ & 1.11 & 1.00 & 1.22 & 0.043 * \\
\hline
\end{tabular}

* Significance of $p<0.05$; Covariates: Preterm birth in first pregnancy; interpregnancy interval; maternal age; race/ethnicity; pre-pregnancy BMI; smoking; alcohol use; parity; insurance status; marital status; asthma history.

Assessing the interaction by prior preterm birth status (Table 3), the risks for persistent high exposure and for increasing exposure over time often appear to be associated with higher risk for women without a prior history of preterm birth, with significant interactions based on preterm birth history for $\mathrm{NO}_{2}, \mathrm{SO}_{2}, \mathrm{O}_{3}$ and $\mathrm{CO}$. When exposure stayed high, $\mathrm{SO}_{2}$ risk was fairly consistent between women with and without a prior history $(21 \%$ vs. $37 \%$ increase, $p$ interaction $=0.33)$, whereas greater risk was observed for $\mathrm{NO}_{2}$ among women without a prior preterm birth compared to women with a prior preterm birth $(56 \%$ vs. $18 \%$ increase, $p$ interaction $=0.025)$. Increasing exposure suggested similar risks by prior preterm birth status for $\mathrm{PM}_{10}(21 \% \mathrm{vs.} 22 \%$, $p$ interaction $=0.90)$, but significantly higher risk for women without a prior preterm birth associated with increasing $\mathrm{NO}_{2}, \mathrm{SO}_{2}, \mathrm{O}_{3}$ and $\mathrm{CO}$ compared to women with a prior preterm birth history. 
Table 3. The adjusted relative risk of preterm birth in second pregnancy by change in whole pregnancy average criteria pollutant exposure levels from first to second pregnancy by prior preterm birth status among 50,005 mothers, NICHD Consecutive Pregnancy Study, 2002-2010.

\begin{tabular}{|c|c|c|c|c|c|c|c|c|c|}
\hline \multirow{2}{*}{$\begin{array}{l}\text { Change in Whole Pregnancy Exposure from First } \\
\text { to Second Observed Pregnancy }\end{array}$} & \multicolumn{4}{|c|}{ Preterm Birth in First Pregnancy } & \multicolumn{4}{|c|}{ No Preterm Birth in First Pregnancy } & \multirow[t]{2}{*}{ Interaction $p$} \\
\hline & $\mathbf{R R}$ & LCL & UCL & $p$ & $\mathbf{R R}$ & LCL & UCL & $p$ & \\
\hline \multicolumn{10}{|l|}{ Stay high vs. stay low } \\
\hline $\mathrm{SO}_{2}$ & 1.21 & 1.00 & 1.46 & 0.052 & 1.37 & 1.17 & 1.59 & $<0.0001$ & 0.33 \\
\hline $\mathrm{O}_{3}$ & 1.16 & 0.91 & 1.47 & 0.22 & 1.18 & 0.96 & 1.45 & 0.11 & 0.90 \\
\hline $\mathrm{NO}_{\mathrm{x}}$ & 1.07 & 0.87 & 1.30 & 0.52 & 1.32 & 1.12 & 1.57 & 0.001 & 0.10 \\
\hline $\mathrm{NO}_{2}$ & 1.18 & 0.97 & 1.43 & 0.10 & 1.56 & 1.34 & 1.81 & $<0.0001$ & 0.025 * \\
\hline $\mathrm{CO}$ & 1.12 & 0.92 & 1.37 & 0.26 & 1.41 & 1.19 & 1.67 & $<0.0001$ & 0.08 \\
\hline $\mathrm{PM}_{2.5}$ & 0.93 & 0.75 & 1.17 & 0.54 & 1.11 & 0.92 & 1.35 & 0.28 & 0.24 \\
\hline $\mathrm{PM}_{10}$ & 1.10 & 0.91 & 1.33 & 0.32 & 1.39 & 1.20 & 1.60 & $<0.0001$ & 0.057 \\
\hline \multicolumn{10}{|l|}{ Stay moderate vs. stay low } \\
\hline $\mathrm{SO}_{2}$ & 1.12 & 0.95 & 1.32 & 0.16 & 1.12 & 0.99 & 1.27 & 0.08 & 0.97 \\
\hline $\mathrm{O}_{3}$ & 0.95 & 0.77 & 1.19 & 0.68 & 0.98 & 0.81 & 1.17 & 0.80 & 0.88 \\
\hline $\mathrm{NO}_{\mathrm{x}}$ & 0.93 & 0.77 & 1.12 & 0.44 & 0.88 & 0.75 & 1.03 & 0.11 & 0.66 \\
\hline $\mathrm{NO}_{2}$ & 0.98 & 0.81 & 1.18 & 0.81 & 0.92 & 0.80 & 1.06 & 0.26 & 0.61 \\
\hline $\mathrm{CO}^{-}$ & 0.93 & 0.77 & 1.12 & 0.45 & 0.88 & 0.75 & 1.03 & 0.11 & 0.66 \\
\hline $\mathrm{PM}_{2.5}$ & 0.77 & 0.64 & 0.94 & 0.008 & 0.85 & 0.73 & 1.00 & 0.05 & 0.45 \\
\hline $\mathrm{PM}_{10}$ & 1.14 & 0.97 & 1.34 & 0.11 & 0.99 & 0.88 & 1.12 & 0.93 & 0.18 \\
\hline \multicolumn{10}{|l|}{ Increase vs. stay low } \\
\hline $\mathrm{SO}_{2}$ & 1.19 & 1.01 & 1.40 & 0.041 & 1.51 & 1.33 & 1.72 & $<0.0001$ & $0.023 *$ \\
\hline $\mathrm{O}_{3}$ & 1.16 & 0.88 & 1.53 & 0.29 & 1.67 & 1.33 & 2.09 & $<0.0001$ & 0.048 * \\
\hline $\mathrm{NO}_{\mathrm{x}}$ & 1.03 & 0.85 & 1.24 & 0.78 & 1.19 & 1.01 & 1.41 & 0.042 & 0.25 \\
\hline $\mathrm{NO}_{2}$ & 1.14 & 0.93 & 1.38 & 0.20 & 1.64 & 1.40 & 1.92 & $<0.0001$ & $0.004 *$ \\
\hline $\mathrm{CO}$ & 1.15 & 0.94 & 1.42 & 0.18 & 1.79 & 1.48 & 2.16 & $<0.0001$ & $0.002 *$ \\
\hline $\mathrm{PM}_{2.5}$ & 0.86 & 0.72 & 1.02 & 0.07 & 1.02 & 0.88 & 1.19 & 0.75 & 0.12 \\
\hline $\mathrm{PM}_{10}$ & 1.21 & 1.02 & 1.43 & 0.028 & 1.22 & 1.07 & 1.40 & 0.003 & 0.90 \\
\hline \multicolumn{10}{|l|}{ Decrease vs. stay low } \\
\hline $\mathrm{SO}_{2}$ & 1.03 & 0.87 & 1.21 & 0.73 & 1.24 & 1.09 & 1.40 & 0.001 & 0.08 \\
\hline $\mathrm{O}_{3}$ & 0.95 & 0.78 & 1.16 & 0.61 & 0.96 & 0.81 & 1.15 & 0.67 & 0.92 \\
\hline $\mathrm{NO}_{\mathrm{x}}$ & 0.99 & 0.83 & 1.17 & 0.90 & 1.04 & 0.90 & 1.21 & 0.59 & 0.65 \\
\hline $\mathrm{NO}_{2}$ & 1.05 & 0.88 & 1.25 & 0.59 & 1.15 & 1.01 & 1.32 & 0.04 & 0.40 \\
\hline $\mathrm{CO}$ & 0.96 & 0.81 & 1.14 & 0.63 & 1.01 & 0.88 & 1.17 & 0.86 & 0.63 \\
\hline $\mathrm{PM}_{2.5}$ & 0.86 & 0.72 & 1.02 & 0.09 & 1.04 & 0.90 & 1.21 & 0.61 & 0.10 \\
\hline $\mathrm{PM}_{10}$ & 1.07 & 0.91 & 1.26 & 0.40 & 1.12 & 0.99 & 1.26 & 0.06 & 0.67 \\
\hline
\end{tabular}

* Significance of $p<0.05$. Covariates: Preterm birth in first pregnancy; interpregnancy interval; maternal age; race/ethnicity; pre-pregnancy BMI; smoking; alcohol use; parity; insurance status; marital status; asthma history. 
Restricting the exposure windows to the first 28 weeks of gestation yielded a similar pattern of results, but the effects were somewhat attenuated (Supplementary Material Table S4). Significant findings remained for $\mathrm{SO}_{2}, \mathrm{NO}_{2}$ and $\mathrm{PM}_{10}$. When considering only women who were nulliparous at the beginning of the study ( $n=27,137,54.3 \%)$, change in exposure over time was associated with a similar pattern of results as the main analysis, although increasing exposure was associated with somewhat higher point estimates in this group (Supplementary Material Table S5). For example, increasing ozone was associated with an $80 \%$ increase in risk among nulliparas compared to a $48 \%$ increase in the full sample. Examining risk by prior preterm birth among nulliparous women at study entry (Supplementary Material Table S6), $\mathrm{O}_{3}$ was associated with increased risk when exposure stayed high regardless of prior preterm birth status, whereas increasing exposure was significantly elevated ( $p$ for interaction > 0.05) among women without a prior preterm birth for $\mathrm{NO}_{2}, \mathrm{CO}$ and $\mathrm{PM}_{2.5}$. Adding year of conception for the second pregnancy or an indicator variable to measure the change in the season of conception from the first to second pregnancy into the models did not substantively change any of the findings (data not shown).

\section{Discussion}

In a cohort of low-risk U.S. women, we found that preterm birth risks were significantly increased in association with persistent high exposure to all criteria air pollutants except for $\mathrm{PM}_{2.5}$. Increasing exposure over time was associated with higher preterm birth risk, while decreasing exposure was associated with lower risk estimates. Women without a prior preterm birth experienced a higher risk for an incident preterm birth in the second pregnancy associated with pollution.

During the study period, our cohort had a preterm birth rate of $7.6 \%$ in comparison to approximately $12 \%$ for the U.S. overall. This low-risk group experienced moderate levels of chronic air pollution exposure and exposure decreased over time for a substantial proportion of the women, ranging from $27 \%$ for $\mathrm{SO}_{2}$ to $59 \%$ for $\mathrm{O}_{3}$. Increasing exposure was less common, experienced by only $3 \%$ of women with respect to $\mathrm{O}_{3}$, but $30-32 \%$ of women had increased $\mathrm{PM}_{2.5}$ exposure in the second observed pregnancy compared to their first. A prior history of preterm birth is a major risk factor for preterm birth in a subsequent pregnancy [10] and, in our data, this was clearly the case. We also observed that women without a prior history generally had higher preterm birth risks associated with air pollution compared to women with a prior preterm birth. Among higher risk women, the marginal increases associated with air pollution were often not statistically significant, probably due to the competing risks of their history and factors associated with that history. In most exposure scenarios, nulliparous women at study entry also had higher preterm birth risk estimates associated with air pollutants. Taken together, these findings support the notion that the strongest preterm birth risks associated with higher air pollution exposure and increasing exposure over time were observed among the lowest risk women, those without a prior history of preterm birth and nulliparas.

In contrast to many studies of preterm birth $[6,13,14]$, we found no increased risk associated with $\mathrm{PM}_{2.5}$ and many of the point estimates we observed were below 1.00. It may be that our chronic average categorization is not an ideal fit for this exposure, given that the Utah Valley experiences inversions and high PM exposures during peak events in the winter. We also noted that nearly one-third of women experienced an increased average $\mathrm{PM}_{2.5}$ exposure between the first and second pregnancy, which may be due to wildfire exposures. A more detailed assessment of short-term $\mathrm{PM}_{2.5}$ exposures is warranted to consider those factors.

This study takes advantage of a nearly decade-long observational cohort with detailed clinical information on women with more than one delivery in a defined geographic area. The women were low-risk, but still experienced significant increases in preterm birth related to moderate levels of criteria air pollutants. Given the rich clinical data available, we were able to adjust for maternal demographic characteristics and factors, such as interpregnancy interval [15], prior preterm birth [10] and maternal asthma [16,17], all of which are known to be associated with preterm risk, but may not be available in administrative data. We are limited in our exposure assessment because we do not have information 
on maternal address and assume that the women live in the area covered by their delivery hospital. Even among women who delivered in two different hospitals over the course of the study period, we assume each delivery hospital referral region estimates their local area exposure for that pregnancy. While this will introduce some measurement error, it will likely be non-differential with respect to subsequent preterm delivery and a more broad local exposure area will account for some local mobility as women move around their neighborhoods to work, school and other activities. We also acknowledge that changes in meteorological factors, such as ambient temperature, have been associated with preterm birth risk independent of air pollution [18] and those exposures merit further research.

Our categorical chronic exposure scenario was chosen to examine the bigger picture changes over time that could reasonably be observed, and that might be associated with policy-relevant changes in preterm birth risk associated with these dynamic exposures. Preterm birth risks associated with changing exposure were not influenced by changes to the season of conception between the first and second birth or adjustment for the year of conception of the second pregnancy.

\section{Conclusions}

In this study of low-risk women with consecutive pregnancies in a large cohort, we observed increased risk over time for nearly all criteria pollutants when exposure remained high or increased over time. Decreases in exposure over time were associated with comparatively lower risk estimates. Women without a prior preterm birth experienced a higher risk for an incident preterm birth in the second pregnancy associated with pollution.

These findings suggest that improvements in air quality could reduce related preterm birth risks, but failure to address persistent air pollution results in higher risk, particularly for nulliparous women and those without a prior preterm birth history.

Supplementary Materials: The following are available online at http://www.mdpi.com/1660-4601/16/18/3365/s1, Table S1: Cutpoints for high, moderate and low exposure levels based on the first observed pregnancy among 50,005 mothers, NICHD Consecutive Pregnancy Study, 2002-2010. Table S2: Distribution of air pollutants in first and second pregnancy for whole pregnancy exposure and average exposure in first 28 weeks of pregnancy among 50,005 mothers, NICHD Consecutive Pregnancy Study, 2002-2010, Table S3: Change in air pollution category from first to second pregnancy by preterm birth in first pregnancy among 50,005 mothers, NICHD Consecutive Pregnancy Study, 2002-2010, Table S4: Adjusted relative risk of preterm birth in second pregnancy by change in average criteria pollutant exposure levels for the first 28 weeks of gestation from first to second pregnancy among 50,005 mothers, NICHD Consecutive Pregnancy Study, 2002-2010, Table S5: Adjusted relative risk of preterm birth in second pregnancy by change in average whole pregnancy criteria pollutant exposure levels from first to second pregnancy among 27,137 nulliparous mothers, NICHD Consecutive Pregnancy Study, 2002-2010, Table S6: Adjusted relative risk of preterm birth in second pregnancy by change in average whole pregnancy criteria pollutant exposure levels from first to second pregnancy by prior preterm birth status among 27,137 nulliparous mothers, NICHD Consecutive Pregnancy Study, 2002-2010.

Author Contributions: Conceptualization: P.M. and C.N.; Methodology: P.M., C.N., A.W., S.S., J.K., I.S. and K.G. made substantial contributions to the design; Formal Analyses: C.N.; Resources: S.S. and P.M. were responsible for the collection of the air data, K.G. leads the NICHD Consecutive Pregnancy Study; Writing-Original Draft: P.M.; Writing-Review and Editing: P.M., C.N., A.W., S.S., J.K., I.S. and K.G.; Supervision: P.M. All authors have substantively revised the work and approved the submitted version. All authors agree to be personally accountable for the author's own contributions and for ensuring that questions related to the accuracy or integrity of any part of the work, even ones in which the author was not personally involved, are appropriately investigated, resolved, and documented in the literature.

Funding: Funding was provided by the Intramural Research Program of the Eunice Kennedy Shriver National Institute for Child Health and Human Development, Consecutive Pregnancy Study Contract Nos. HHSN275200800002I, HH2N27500004 and the Air Quality and Reproductive Health Study Contract No. HHSN275200800002I, Task Order No. HHSN27500008.

Conflicts of Interest: The authors declare no conflict of interest. The manuscript is cleared for publication by the $\mathrm{NIH}$, but the funding source had no role in the design, execution, interpretation, or writing of the study.

\section{References}

1. Laughon, S.K.; Albert, P.S.; Leishear, K.; Mendola, P. The NICHD Consecutive Pregnancies Study: Recurrent preterm delivery by subtype. Am. J. Obstet. Gynecol. 2014, 210, 131. [CrossRef] [PubMed] 
2. US Environmental Protection Agency. Our Nation's Air: Status and Trends Through 2010; US Environmental Protection Agency: Research Triangle Park, NC, USA, 2012.

3. Martin, J.A.; Osterman, M.J. Centers for Disease Control and Prevention. Preterm births-United States, 2006 and 2010. MMWR 2013, 62, 136-138.

4. Orru, H.; Ebi, K.L.; Forsberg, B. The Interplay of Climate Change and Air Pollution on Health. Curr. Environ. Health Rep. 2017, 4, 504-513. [CrossRef] [PubMed]

5. Kinney, P.L. Interactions of Climate Change, Air Pollution, and Human Health. Curr. Environ. Health Rep. 2018, 5, 179-186. [CrossRef] [PubMed]

6. Klepac, P.; Locatelli, I.; Korosec, S.; Kunzli, N.; Kukec, A. Ambient air pollution and pregnancy outcomes: A comprehensive review and identification of environmental public health challenges. Environ. Res. 2018, 167, 144-159. [CrossRef] [PubMed]

7. Purisch, S.E.; Gyamfi-Bannerman, C. Epidemiology of preterm birth. Semin. Perinatol. 2017, 41, $387-391$. [CrossRef] [PubMed]

8. Luu, T.M.; Rehman Mian, M.O.; Nuyt, A.M. Long-Term Impact of Preterm Birth: Neurodevelopmental and Physical Health Outcomes. Clin. Perinatol. 2017, 44, 305-314. [CrossRef] [PubMed]

9. Casey, J.A.; Karasek, D.; Ogburn, E.L.; Goin, D.E.; Dang, K.; Braveman, P.A.; Morello-Frosch, R. Retirements of Coal and Oil Power Plants in California: Association With Reduced Preterm Birth Among Populations Nearby. Am. J. Epidemiol. 2018, 187, 1586-1594. [CrossRef] [PubMed]

10. Phillips, C.; Velji, Z.; Hanly, C.; Metcalfe, A. Risk of recurrent spontaneous preterm birth: A systematic review and meta-analysis. BMJ Open 2017, 7, e015402. [CrossRef] [PubMed]

11. Chen, G.; Li, J.; Ying, Q.; Sherman, S.; Perkins, N.; Sundaram, R.; Mendola, P. Evaluation of observation-fused regional air quality model results for population air pollution exposure estimation. Sci. Total Environ. 2014, 485, 563-574. [CrossRef] [PubMed]

12. Van Buuren, S. Multiple imputation of discrete and continuous data by fully conditional specification. Stat. Methods Med. Res. 2007, 16, 219-242. [CrossRef] [PubMed]

13. Malley, C.S.; Kuylenstierna, J.C.; Vallack, H.W.; Henze, D.K.; Blencowe, H.; Ashmore, M.R. Preterm birth associated with maternal fine particulate matter exposure: A global, regional and national assessment. Environ. Int. 2017, 101, 173-182. [CrossRef] [PubMed]

14. Liu, C.; Sun, J.; Liu, Y.; Liang, H.; Wang, M.; Wang, C.; Shi, T. Different exposure levels of fine particulate matter and preterm birth: A meta-analysis based on cohort studies. Environ. Sci. Pollut. Res. Int. 2017, 24, 17976-17984. [CrossRef] [PubMed]

15. Koullali, B.; Kamphuis, E.I.; Hof, M.H.; Robertson, S.A.; Pajkrt, E.; de Groot, C.J.; Mol, B.W.; Ravelli, A.C. The Effect of Interpregnancy Interval on the Recurrence Rate of Spontaneous Preterm Birth: A Retrospective Cohort Study. Am. J. Perinatol. 2017, 34, 174-182. [CrossRef] [PubMed]

16. Mendola, P.; Wallace, M.; Hwang, B.S.; Liu, D.; Robledo, C.; Mannisto, T.; Sundaram, R.; Sherman, S.; Ying, Q.; Grantz, K.L. Preterm birth and air pollution: Critical windows of exposure for women with asthma. J. Allergy Clin. Immunol. 2016, 138, 432-440. [CrossRef] [PubMed]

17. Mendola, P.; Mannisto, T.I.; Leishear, K.; Reddy, U.M.; Chen, Z.; Laughon, S.K. Neonatal health of infants born to mothers with asthma. J. Allergy Clin. Immunol. 2014, 133, 85-90. [CrossRef] [PubMed]

18. Ha, S.; Liu, D.; Zhu, Y.; Kim, S.S.; Sherman, S.; Mendola, P. Ambient temperature and early delivery of singleton pregnancies. Environ. Health Perspect. 2017, 125, 453-459. [CrossRef] [PubMed]

(C) 2019 by the authors. Licensee MDPI, Basel, Switzerland. This article is an open access article distributed under the terms and conditions of the Creative Commons Attribution (CC BY) license (http://creativecommons.org/licenses/by/4.0/). 